\title{
Assessment of inflammation in patients with arrhythmogenic right ventricular cardiomyopathy/dysplasia
}

\author{
Maria E. Campian • Hein J. Verberne • Maxim Hardziyenka • \\ Elisabeth A. A. de Groot • Astrid F. van Moerkerken • Berthe L. F. van Eck-Smit • \\ Hanno L. Tan
}

Received: 12 April 2010 / Accepted: 3 June 2010 /Published online: 6 July 2010

(C) The Author(s) 2010. This article is published with open access at Springerlink.com

\begin{abstract}
Purpose Arrhythmogenic right ventricular cardiomyopathy/ dysplasia (ARVC/D) is a myocardial disease that predominantly affects the right ventricle (RV). Its hallmark feature is fibro-fatty replacement of RV myocardium. However, patchy inflammatory infiltrates in the RV are also consistently reported using autopsy and myocardial biopsy. Although the role of inflammation in ARVC/D is unresolved, the ability to assess inflammation non-invasively may aid in the diagnostic process. We aimed to establish whether cardiac inflammation can be assessed non-invasively in ARVC/D patients.

Methods In eight ARVC/D patients and nine controls (haematology/oncology patients), the level of inflammatory activation was assessed by measuring plasma levels of inflammatory cytokines. Regional myocardial inflammation was assessed with ${ }^{67} \mathrm{Ga}$ scintigraphy.

Results ARVC/D patients had higher plasma levels than controls of the pro-inflammatory cytokines interleukin (IL)$1 \beta(1.22 \pm 0.07$ vs $0.08 \pm 0.01 \mathrm{pg} / \mathrm{ml}, p<0.0001)$, IL-6 (3.16 \pm
\end{abstract}

M. E. Campian · M. Hardziyenka • E. A. A. de Groot •

H. L. Tan $(\bowtie)$

Heart Failure Research Center, Academic Medical Center,

University of Amsterdam,

Meibergdreef 9 ,

1105 Amsterdam, The Netherlands

e-mail: h.l.tan@amc.nl

H. J. Verberne - A. F. van Moerkerken - B. L. F. van Eck-Smit Department of Nuclear Medicine, Academic Medical Center, University of Amsterdam,

Amsterdam, The Netherlands

\section{H. L. Tan}

Department of Cardiology, Academic Medical Center,

University of Amsterdam,

Amsterdam, The Netherlands
0.44 vs $0.38 \pm 0.04 \mathrm{pg} / \mathrm{ml}, p<0.0001)$ and tumour necrosis factor (TNF)- $\alpha(9.16 \pm 0.90 \mathrm{vs} 0.40 \pm 0.06 \mathrm{pg} / \mathrm{ml}, p<0.0001$ ), while levels of the anti-inflammatory cytokine IL-10 were not significantly different $(1.36 \pm 0.15 \mathrm{vs} 1.20 \pm 0.30 \mathrm{pg} / \mathrm{ml}$, $p=0.74) .{ }^{67} \mathrm{Ga}$ uptake in the RV was higher in ARVC/D patients than in controls. In ARVC/D patients, ${ }^{67} \mathrm{Ga}$ uptake in the RV wall was higher than in the interventricular septum or left ventricular wall.

Conclusion Inflammation in the RV wall of ARVC/D patients can be detected non-invasively with the combined analysis of plasma levels of inflammatory cytokines and cardiac ${ }^{67} \mathrm{Ga}$ scintigraphy.

Keywords Arrhythmogenic right ventricular cardiomyopathy/dysplasia $\cdot$ Inflammatory cytokines . Scintigraphy $\cdot{ }^{67} \mathrm{Ga}$

$\begin{array}{ll}\begin{array}{l}\text { Abbreviations } \\ \text { ARVC/D }\end{array} & \begin{array}{l}\text { Arrhythmogenic right ventricular } \\ \text { cardiomyopathy/dysplasia }\end{array} \\ \text { IL-1 } \beta & \text { Interleukin } 1 \text { beta } \\ \text { IL-6 } & \text { Interleukin } 6 \\ \text { IL-10 } & \text { Interleukin } 10 \\ \text { IVS } & \text { Interventricular septum } \\ \text { LV } & \text { Left ventricle/ventricular } \\ \text { ROI } & \text { Region of interest } \\ \text { RV } & \text { Right ventricle/ventricular } \\ \text { TNF- } \alpha & \text { Tumour necrosis factor alpha }\end{array}$

\section{Introduction}

Arrhythmogenic right ventricular cardiomyopathy/dysplasia $(\mathrm{ARVC} / \mathrm{D})$ is a myocardial disease that predominantly 
affects the right ventricle (RV), although biventricular involvement may occur in advanced cases [1]. ARVC/D is characterized by structural derangements that may cause a broad range of signs and symptoms. Yet, disease expression is highly variable and incomplete in most patients, confounding both the diagnostic process and clinical management, particularly at early disease stages [2].

The histopathological hallmark of ARVC/D is fibrofatty replacement of RV myocardium [3]. Nevertheless, patchy inflammatory infiltrates in the RV are also consistently reported $[3,4]$. How fibro-fatty replacement and inflammatory infiltrates are related is a matter of speculation.

It has been proposed that the progressive loss of RV myocardium is caused by an inflammatory injury and that subsequent fibro-fatty replacement is part of a healing process [3-5].

At present, detection of myocardial inflammation requires the use of endomyocardial biopsies or analysis of autopsy material. Although sampling of endomyocardial biopsies is relatively safe, particularly when guided by electroanatomical mapping [6], the availability of noninvasive diagnostic tools would provide obvious advantages for clinical practice. Thus far, the pro-inflammatory cytokines [interleukin-1 $\beta$ (IL-1 $\beta$ ), interleukin-6 (IL-6) and tumour necrosis factor- $\alpha$ (TNF- $\alpha)$ ] have been shown to be activated and to play a role in chamber dysfunction in patients with left ventricular (LV) heart failure [7, 8]. Yet, in ARVC/D, there are no data on possible activation and detection of the pro-inflammatory cytokines. Although the pro-inflammatory cytokines are possibly sensitive markers for disease state, the interpretation is hampered by the lack of organ-specific identification. In addition to systemic evaluation, localization of disease to the myocardium is essential. Previously, we have shown that activation of inflammatory infiltrates in the ventricular myocardium can be non-invasively detected with the use of ${ }^{67} \mathrm{Ga}$ scintigraphy [9]. Therefore, the aim of the present study was to test whether inflammation in ARVC/D may be monitored noninvasively with the complementary use of plasma inflammatory cytokine analysis and cardiac ${ }^{67} \mathrm{Ga}$ scintigraphy.

\section{Materials and methods}

Patients and control subjects

The Institutional Review Board approved the study protocol and informed consent was obtained from all study subjects. Eight ARVC/D patients and nine controls were examined. All patients were diagnosed with the use of the ARVC/D Task Force criteria [10] and were randomly taken from the cohort of ARVC/D patients at our institution, a tertiary referral centre. Patients were included if they were in clinically stable condition (no ventricular tachyarrhythmias or heart failure symptoms in the 2 months before inclusion). Genetic analysis for plakophilin 2 (PKP2), desmoplakin (DSP), desmoglein 2 (DSG2), desmocollin 2 (DSC2), plakoglobin (JUP) and transmembrane protein 43 (TMEM43) was conducted in all patients or the probands in their family [11, 12]. Controls were retrospectively taken from our institution's haematological/oncological database and were individuals in whom ${ }^{67} \mathrm{Ga}$ scintigraphy was routinely performed in their diagnostic work-up. Their primary disease locus was extrathoracic, and the acquisition was made before any form of chemotherapy or radiotherapy. Neither ARVC/D patients nor controls had a history of coronary artery disease, diabetes or hypertension.

Plasma level of inflammatory cytokines

We analysed plasma levels of pro-inflammatory cytokines (IL-1 $\beta$, IL-6, TNF- $\alpha$ ) and the anti-inflammatory cytokine interleukin-10 (IL-10) using commercially available ultrasensitive enzyme-linked immunosorbent assay (ELISA) kits for human IL-1 $\beta$, IL-6, TNF- $\alpha$ and IL-10 according to the manufacturer's recommendations (Bio-Rad Laboratories, Hercules, CA, USA). The $95 \%$ confidence interval of the in-hospital reference values obtained in 62 healthy volunteers were for IL-1 $\beta$ : $0.0018-0.2118 \mathrm{pg} / \mathrm{ml}$, for IL-6: $0.0895-1.2238 \mathrm{pg} / \mathrm{ml}$, for TNF- $\alpha$ : $0.0212-2.2556 \mathrm{pg} / \mathrm{ml}$ and for IL-10: $0.0483-16.7000 \mathrm{pg} / \mathrm{ml}$.

${ }^{67}$ Ga scintigraphy

SPECT of the thorax was performed $48 \mathrm{~h}$ after an intravenous injection of $200 \mathrm{MBq}$ of ${ }^{67} \mathrm{Ga}$-citrate by use of a gamma camera (Infinia, General Electric, Milwaukee, WI, USA) with a medium energy all purpose collimator and a $128 \times 128$ matrix. Fifteen perc ent windows were set for the three main energy peaks of ${ }^{67} \mathrm{Ga}(93,184$ and $296 \mathrm{keV})$. SPECT images were iteratively reconstructed (ordered subset expectation maximization,OSEM) and corrected for attenuation using the low-dose CT of the Infinia (no intravenous contrast). To define the anatomical borders of the myocardium within the thorax, anatomical tomographic images are essential and the low-dose CT images of the Infinia could not be used for this purpose. Therefore, tomographic anatomical images (contrast-enhanced CT or cardiac MRI), performed prior to implantable cardioverterdefibrillator (ICD) implantation (within 6 months of ${ }^{67} \mathrm{Ga}$ scintigraphy), were retrieved for all subjects. To align the anatomical images with the SPECT data, first the matrix size of the anatomical images was adjusted to the SPECT matrix size $(128 \times 128)$ and secondly the images were 
automatically aligned (MultiModality, HERMES Medical Solutions, Stockholm, Sweden). To semi-quantify ${ }^{67} \mathrm{Ga}$ myocardial uptake, three regions of interest (ROI) [RV wall, interventricular septum (IVS) and LV free wall] were drawn on three summed mid-myocardial horizontal long axis anatomical images. These ROIs on the anatomical images were copied to the aligned SPECT images. ${ }^{67} \mathrm{Ga}$ uptake in each separate ROI was calculated as the ratio of mean counts per pixel in the specific myocardial region over mean counts per pixel in the total myocardium (the sum of all three ROIs).

\section{Statistical analysis}

Data are presented as mean $\pm \mathrm{SD}$. Mean values were compared for differences using the (un)paired Student's $t$ test when appropriate. In cases of multiple comparisons, means were compared for differences with analysis of variance (two-way ANOVA) using a post hoc Bonferroni correction. The correlation coefficient was used to study possible associations between plasma levels of inflammatory cytokines and myocardial ${ }^{67} \mathrm{Ga}$ uptake (SPSS for Windows 15.1, SPSS Inc., Chicago, IL, USA). A $p$ value $<$ 0.05 was considered to indicate statistical significance.

\section{Results}

Patient characteristics

Table 1 summarizes the demographic/clinical data and the presence/absence of the ARVC/D criteria in the ARVC/D patients. All ARVC/D patients fulfilled the ARVC/D Task Force criteria [13]. Their mean age was $36.8 \pm 13.3$ years (range: $20-55$ years) and $62.5 \%(n=5)$ were female. One patient had the C796R mutation in PKP2, while one had the $\mathrm{V} 158 \mathrm{G}$ mutation in DSG2. Both variants were previously reported as ARVC/D-causing mutations [11, 14]. There were no clinical signs of heart failure and echocardiography revealed normal LV function (not shown). The mean age of controls was $55.4 \pm 11.9$ and $22.2 \%(n=2)$ were female.

\section{Plasma levels of inflammatory cytokines}

The ARVC/D patients had higher plasma levels than controls of the pro-inflammatory cytokines IL-1 $\beta(1.22 \pm$ 0.07 vs $0.08 \pm 0.01 \mathrm{pg} / \mathrm{ml}, p<0.0001)$, IL-6 (3.16 \pm 0.44 vs $0.38 \pm 0.04 \mathrm{pg} / \mathrm{ml}, p<0.0001)$ and TNF- $\alpha(9.16 \pm 0.90 \mathrm{vs}$ $0.40 \pm 0.06 \mathrm{pg} / \mathrm{ml}, p<0.0001)$. The levels of the antiinflammatory cytokine IL-10 were statistically not significantly different between both groups $(1.36 \pm 0.15$ vs $1.20 \pm$ $0.30 \mathrm{pg} / \mathrm{ml}, p=0.72$ ) (Fig. 1).

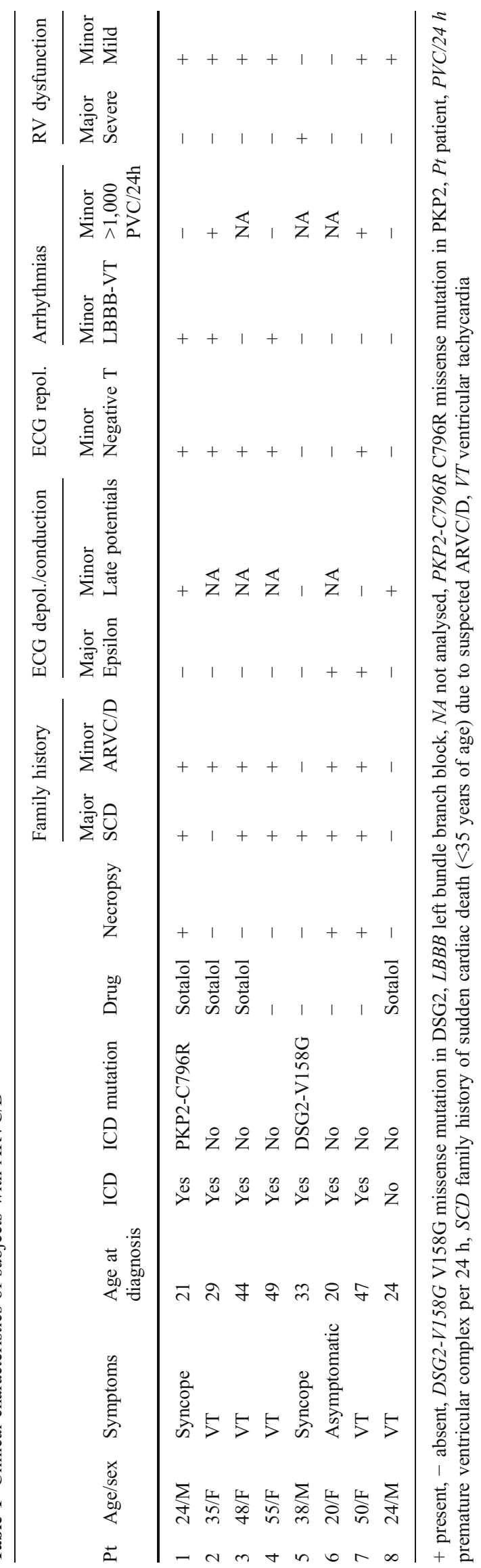



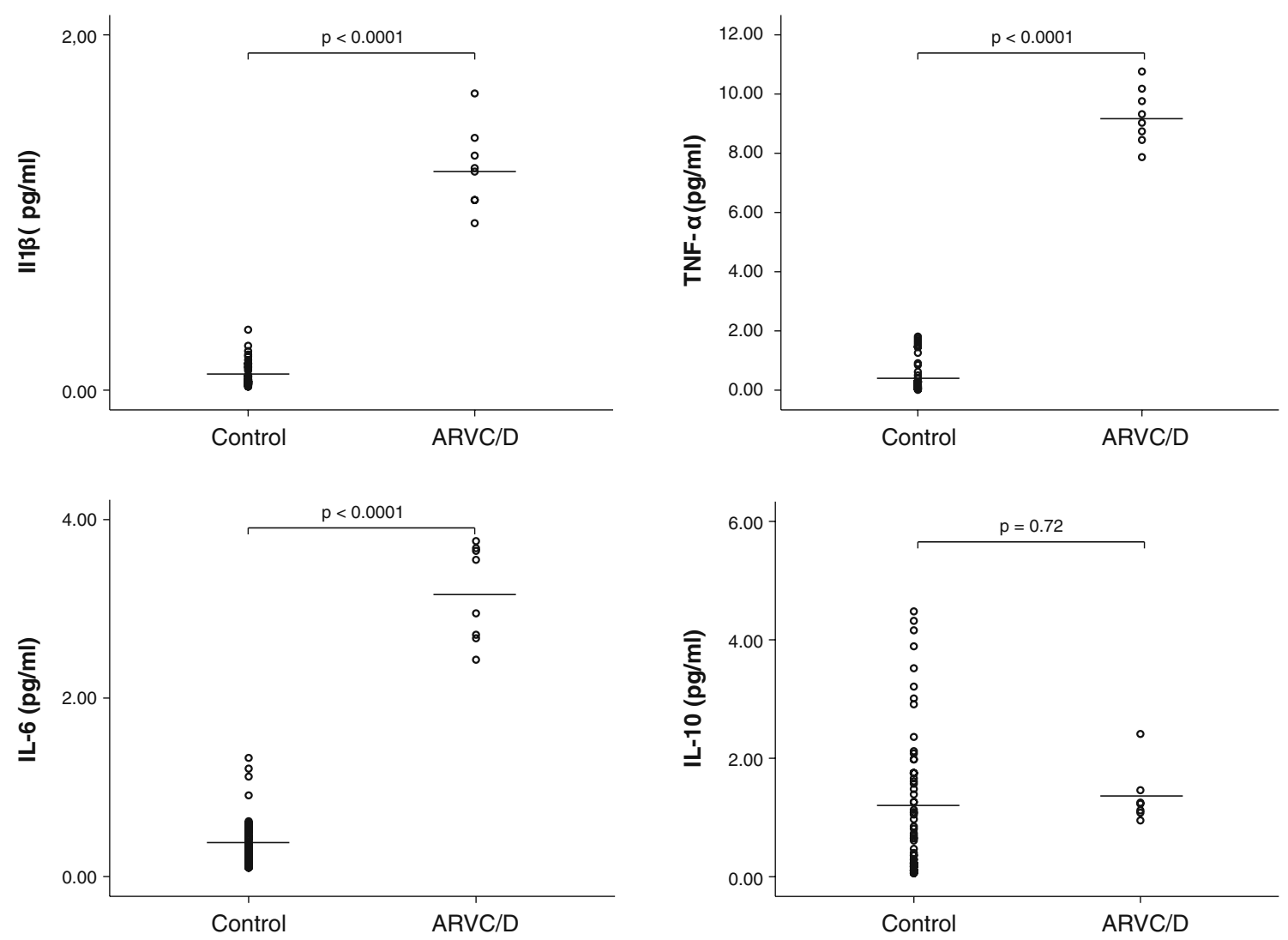

Fig. 1 Plasma concentrations of cytokines in ARVC/D patients and controls. $I L-1 \beta$ interleukin-1 beta, $I L-6$ interleukin-6, $I L-10$ interleukin-10, $T N F-\alpha$ tumour necrosis factor alpha

\section{Myocardial ${ }^{67} \mathrm{Ga}$ uptake}

Figure 2 shows a typical example of an ARVC/D patient with increased ${ }^{67} \mathrm{Ga}$ uptake in the RV wall. ARVC/D patients had significantly higher uptake of ${ }^{67} \mathrm{Ga}$ in the RV wall and IVS than in the LV wall $(1.11 \pm 0.08,1.04 \pm 0.06$ and $0.89 \pm 0.06$, respectively, Fig. 3a). In controls, no differences between these regions were observed $(0.97 \pm$ $0.11,1.04 \pm 0.05$ and $0.99 \pm 0.04$, respectively, Fig. 3b). Moreover, ${ }^{67} \mathrm{Ga}$ uptake in the RV wall was significantly higher in ARVC/D patients than in controls $(1.11 \pm 0.08$ vs $0.97 \pm 0.11, p=0.01)$, while ${ }^{67} \mathrm{Ga}$ uptake was not different between both groups in the IVS $(1.04 \pm 0.06$ vs $1.04 \pm 0.05$, $p=0.90)$ and $\mathrm{LV}$ wall $(0.89 \pm 0.06$ vs $0.99 \pm 0.04, p=0.06)$.
Fig. 2 ARVC/D patient with increased ${ }^{67} \mathrm{Ga}$ uptake in the RV wall. Coregistered transaxial images of cardiac magnetic resonance imaging (left) and ${ }^{67} \mathrm{Ga}$ SPECT scintigraphy (right). There is increased ${ }^{67} \mathrm{Ga}$ uptake in the right ventricular $(R V)$ wall. IVS interventricular septum, $L V$ left ventricular free wall

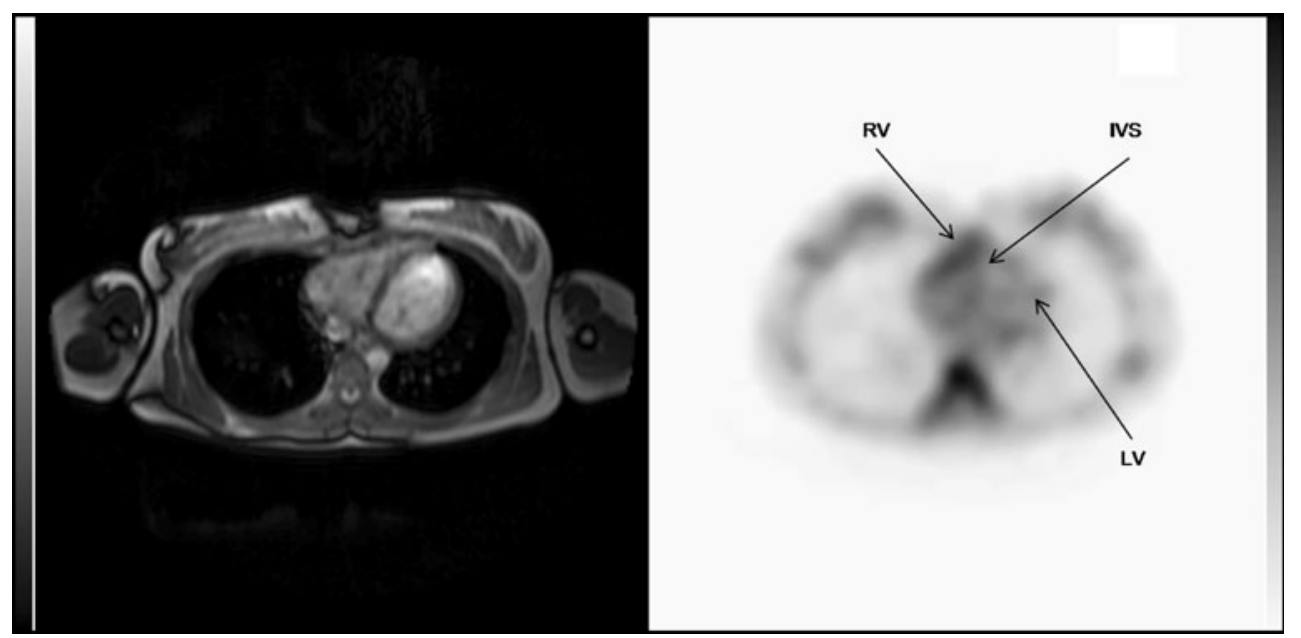


Fig. 3 Myocardial ${ }^{67} \mathrm{Ga}$ uptake in $\mathrm{ARVC} / \mathrm{D}$ patients and controls. Semi-quantitative myocardial ${ }^{67} \mathrm{Ga}$ uptake in ARVC/D subjects (a) and controls (b)

${ }^{67} \mathrm{Ga}$ uptake in the RV wall, interventricular septum (IVS) or LV wall was calculated as the ratio of uptake (mean counts per pixel) in this myocardial region over the uptake in the total myocardium (i.e., the sum of all three ROIs)
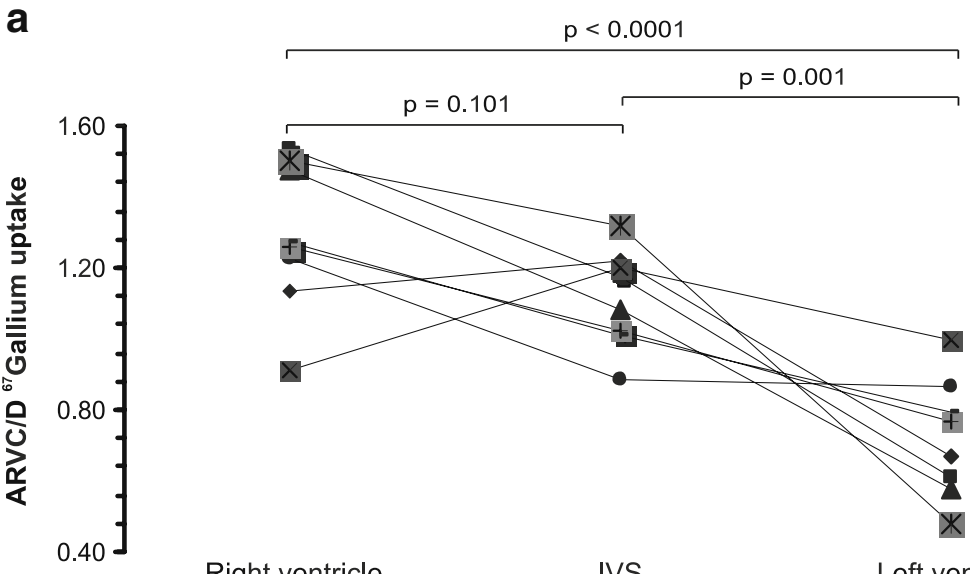

Right ventricle

IVS

Left ventricle
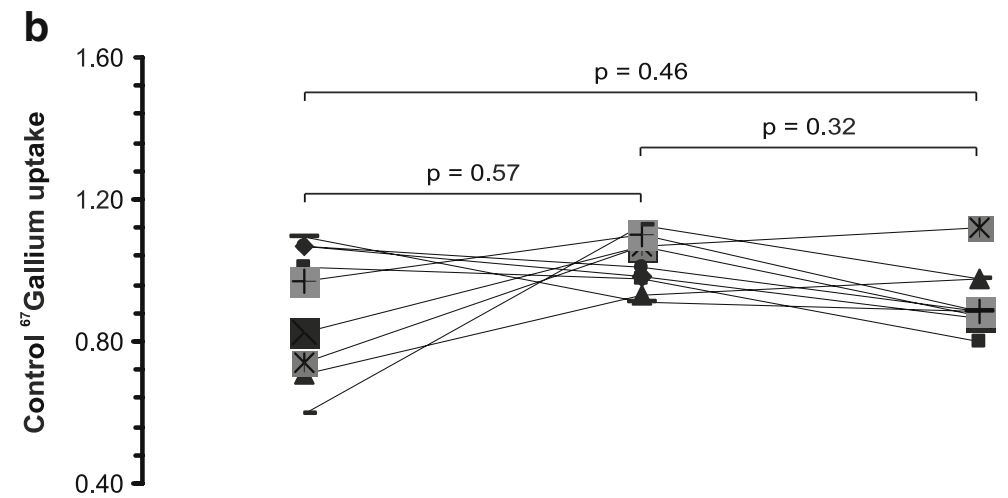

Right ventricle

IVS
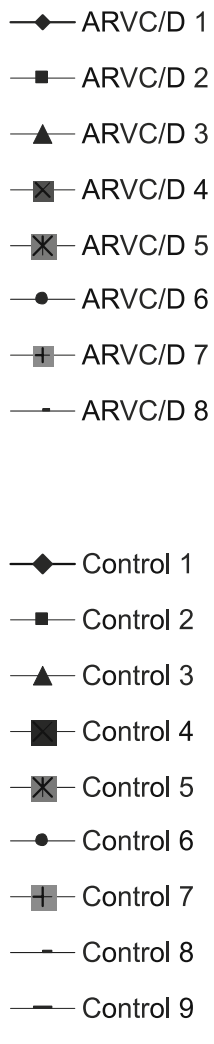

Correlations between plasma levels of inflammatory cytokines and myocardial ${ }^{67} \mathrm{Ga}$ uptake

Plasma levels of IL-1 $\beta$ and ${ }^{67} \mathrm{Ga}$ uptake in the RV appeared to correlate positively, but this correlation did not reach statistical significance $(r=0.62, p=0.1)$. No correlations were found between plasma levels of IL-6, TNF- $\alpha$ or IL-10 and the ${ }^{67} \mathrm{Ga}$ uptake in the RV wall. Similarly, no correlations were found between plasma levels of IL-6, TNF- $\alpha$ or IL-10 and ${ }^{67} \mathrm{Ga}$ uptake in the LV wall or IVS.

\section{Discussion}

With a combined analysis of plasma level of inflammatory cytokines and cardiac ${ }^{67} \mathrm{Ga}$ scintigraphy, we demonstrate that myocardial inflammation can be non-invasively detected in ARVC/D patients.

The pathophysiology behind the loss of RV myocardium in ARVC/D is unresolved. A common finding is patchy cell death with inflammatory infiltration [15]. This has spawned the proposal that ARVC/D has an infectious/ inflammatory aetiology, involving a primary chronic myocarditis that evokes an inflammatory injury and culminates in fibro-fatty repair and progressive loss of RV myocardium. Different types of cardiotropic viruses may play a role in the pathophysiology of ARVC/D. A genetic predisposition may lead to increased viral susceptibility and myocarditis [16].

One explanation for the presence of pro-inflammatory cytokines in ARVC/D is the "cytokine hypothesis" of heart failure, which proposes that a precipitating event triggers innate stress response [17]. These cytokines are believed to be produced by nucleated cells in the heart and subsequently released into the bloodstream [18]. In patients with LV heart failure, pro-inflammatory cytokines contribute, by various mechanisms, to the deterioration of cardiovascular function $[7,8,17]$. Furthermore, various cytokines, including TNF- $\alpha$, IL-2, interferon- $\gamma$ and IL-1 $\beta$-converting enzyme, are increased in viral myocarditis [19]. In ARVC/D, no data on a possible association between pro-inflammatory cytokines and disease are available.

Inflammatory mediators such as TNF- $\alpha$ and IL-1 $\beta$, known to be elevated in viral myocarditis, can stimulate the expression of inducible nitric oxide synthase (iNOS) [20]. Induction of iNOS leads to strand breaks, p53 accumulation and apoptosis, and these processes were 
prevented by iNOS inhibition [21]. Apoptosis, in turn, evokes an inflammatory response.

The inflammatory response in ARVC/D may not only be an initial response to a noxious trigger (e.g. viral infection), but it may also be enhanced because of apoptosis induced by pro-inflammatory cytokines. Our findings (increased plasma levels of pro-inflammatory cytokines and ${ }^{67} \mathrm{Ga}$ uptake in the RV wall) did not allow us to distinguish whether they indicated an initial response to infection or a secondary inflammatory response induced by apoptosis. Moreover, to determine whether inflammation is a viralrelated inflammation or a post-apoptosis inflammatory reaction, it is essential to perform endomyocardial biopsies.

Although pro-inflammatory cytokines may be sensitive disease markers, they cannot localize the disease to a specific organ. Previously, we reported that ${ }^{67} \mathrm{Ga}$ scintigraphy can be used to map inflammation non-invasively in the ventricular myocardium [9]. Although ${ }^{67} \mathrm{Ga}$ scintigraphy has a high sensitivity, a major disadvantage of ${ }^{67} \mathrm{Ga}$ scintigraphy is its limited specificity $[22,27]$. In recent years, ${ }^{18}$ F-fluorodeoxyglucose positron emission tomography $\left({ }^{18} \mathrm{~F}\right.$-FDG PET) has emerged as an alternative and superior method to assess inflammation. However, one of the preferred substrates of myocardial metabolism is glucose. This limits the use of ${ }^{18} \mathrm{~F}-\mathrm{FDG}$ for the detection of localized myocardial inflammation. Therefore, ${ }^{67} \mathrm{Ga}$ scintigraphy is most likely to be superior to ${ }^{18} \mathrm{~F}-\mathrm{FDG}$ for the detection of myocardial muscle inflammation, despite its limited specificity. ${ }^{67} \mathrm{Ga}$ thus marks areas of inflammation (e.g. an infection site) and rapid cell division, allowing sites with tumour, inflammation, and both acute and chronic infection to be visualized with scintigraphic techniques [23-26]. Controversial data were reported in cases of inflammatory foci in myocarditis.

Study limitations and clinical usefulness

Firstly, a limitation of our study is the small number of patients. The finding that the correlations between plasma levels of pro-inflammatory cytokines and myocardial uptake of ${ }^{67} \mathrm{Ga}$ in the RV wall failed to reach statistical significance probably relates to this limited number. Still, the results were highly consistent, as both plasma levels of pro-inflammatory cytokines and myocardial ${ }^{67} \mathrm{Ga}$ uptake in the RV wall were increased in ARVC/D patients. Secondly, it was recently suggested that $\mathrm{ARVC} / \mathrm{D}$ and myocarditis cannot be distinguished with the use of currently established clinical criteria and that a distinction requires analysis of biopsy specimens [6]. Although we conducted no cardiac biopsies, we obtained support for the notion that we studied patients with ARVC/D, rather than myocarditis, by including six patients (patients 1, 2, 3, 4, 6 and 7) who had first-degree relatives that also fulfilled established criteria for ARVC/D and one other patient (patient 5) with a mutation that was previously reported to be associated with ARVC/D.

\section{Conclusion}

Inflammation may contribute to disease progression in ARVC/D and can be assessed non-invasively with the combined analysis of plasma inflammatory cytokine levels and cardiac ${ }^{67} \mathrm{Ga}$ scintigraphy. The ability to detect inflammation non-invasively provides us with a tool that may be used to obtain a better understanding of the role of inflammation in the pathophysiology of ARVC/D as it does in other diseases [27, 28]. The clinical implications of these findings remain to be assessed in future studies.

Grant support Dr. H.L. Tan was supported by the Royal Netherlands Academy of Arts and Sciences (KNAW) and the Netherlands Organization for Scientific Research (NWO, ZonMW-Vici 918.86.616).

Conflicts of interest None.

Open Access This article is distributed under the terms of the Creative Commons Attribution Noncommercial License which permits any noncommercial use, distribution, and reproduction in any medium, provided the original author(s) and source are credited.

\section{References}

1. Asimaki A, Tandri H, Huang H, Halushka MK, Gautam S, Basso $\mathrm{C}$, et al. A new diagnostic test for arrhythmogenic right ventricular cardiomyopathy. N Engl J Med 2009;360:1075-84.

2. Marcus FI, Zareba W, Calkins H, Towbin JA, Basso C, Bluemke DA, et al. Arrhythmogenic right ventricular cardiomyopathy/ dysplasia clinical presentation and diagnostic evaluation: results from the North American Multidisciplinary Study. Heart Rhythm 2009;6:984-92.

3. Basso C, Thiene G, Corrado D, Angelini A, Nava A, Valente M. Arrhythmogenic right ventricular cardiomyopathy. Dysplasia, dystrophy, or myocarditis? Circulation 1996;94:983-91.

4. Tabib A, Loire RR, Chalabreysse L, Meyronnet D, Miras A, Malicier D, et al. Circumstances of death and gross and microscopic observations in a series of 200 cases of sudden death associated with arrhythmogenic right ventricular cardiomyopathy and/or dysplasia. Circulation 2003;108:3000-5.

5. Thiene G, Nava A, Corrado D, Rossi L, Pennelli N. Right ventricular cardiomyopathy and sudden death in young people. $\mathrm{N}$ Engl J Med 1988;318:129-33.

6. Pieroni M, Dello Russo A, Marzo F, Pelargonio G, Casella M, Bellocci $F$, et al. High prevalence of myocarditis mimicking arrhythmogenic right ventricular cardiomyopathy: differential diagnosis by electroanatomic mapping-guided endomyocardial biopsy. J Am Coll Cardiol 2009;53:681-9.

7. Pagani FD, Baker LS, Hsi C, Knox M, Fink MP, Visner MS. Left ventricular systolic and diastolic dysfunction after infusion of tumor necrosis factor-alpha in conscious dogs. J Clin Invest 1992;90:389-98. 
8. Mann DL, Young JB. Basic mechanisms in congestive heart failure. Recognizing the role of proinflammatory cytokines. Chest 1994;105:897-904.

9. Campian ME, Hardziyenka M, de Bruin K, van Eck-Smit BLF, de Bakker JMT, Verberne HJ, et al. Early inflammatory response during development of right ventricular heart failure in a rat model. Eur J Heart Fail 2010;12:653-8.

10. Corrado D, Fontaine G, Marcus FI, McKenna WJ, Nava A, Thiene G, et al. Arrhythmogenic right ventricular dysplasia/ cardiomyopathy: need for an international registry. Study Group on Arrhythmogenic Right Ventricular Dysplasia/Cardiomyopathy of the Working Groups on Myocardial and Pericardial Disease and Arrhythmias of the European Society of Cardiology and of the Scientific Council on Cardiomyopathies of the World Heart Federation. Circulation 2000;101:E101-6.

11. Awad MM, Calkins H, Judge DP. Mechanisms of disease: molecular genetics of arrhythmogenic right ventricular dysplasia/ cardiomyopathy. Nat Clin Pract Cardiovasc Med 2008;5:258-67.

12. Merner ND, Hodgkinson KA, Haywood AF, Connors S, French VM, Drenckhahn JD, et al. Arrhythmogenic right ventricular cardiomyopathy type 5 is a fully penetrant, lethal arrhythmic disorder caused by a missense mutation in the TMEM43 gene. Am J Hum Genet 2008;82:809-21.

13. McKenna WJ, Thiene G, Nava A, Fontaliran F, BlomstromLundqvist C, Fontaine G, et al. Diagnosis of arrhythmogenic right ventricular dysplasia/cardiomyopathy. Task Force of the Working Group Myocardial and Pericardial Disease of the European Society of Cardiology and of the Scientific Council on Cardiomyopathies of the International Society and Federation of Cardiology. Br Heart J 1994;71:215-8.

14. van Tintelen JP, Entius MM, Bhuiyan ZA, Jongbloed R, Wiesfeld $\mathrm{AC}$, Wilde AA, et al. Plakophilin-2 mutations are the major determinant of familial arrhythmogenic right ventricular dysplasia/ cardiomyopathy. Circulation 2006;113:1650-8.

15. Basso C, Ronco F, Marcus F, Abudureheman A, Rizzo S, Frigo $\mathrm{AC}$, et al. Quantitative assessment of endomyocardial biopsy in arrhythmogenic right ventricular cardiomyopathy/dysplasia: an in vitro validation of diagnostic criteria. Eur Heart J 2008;29:2760-71.

16. Calabrese F, Basso C, Carturan E, Valente M, Thiene G. Arrhythmogenic right ventricular cardiomyopathy/dysplasia: is there a role for viruses? Cardiovasc Pathol 2006;15:11-7.
17. Levine B, Kalman J, Mayer L, Fillit HM, Packer M. Elevated circulating levels of tumor necrosis factor in severe chronic heart failure. N Engl J Med 1990;323:236-41.

18. Anker SD, von Haehling S. Inflammatory mediators in chronic heart failure: an overview. Heart 2004;90:464-70.

19. Freeman GL, Colston JT, Zabalgoitia M, Chandrasekar B. Contractile depression and expression of proinflammatory cytokines and iNOS in viral myocarditis. Am J Physiol 1998;274: H249-58.

20. Geng Y, Petersson A, Wennmalm A, Hansson GK. Cytokineinduced expression of nitric oxide synthase results in nitrosylation of heme and nonheme iron proteins in vascular smooth muscle cells. Exp Cell Res 1994;214:418-28.

21. Messmer UK, Lapetina EG, Brüne B. Nitric oxide-induced apoptosis in RAW 264.7 macrophages is antagonized by protein kinase C- and protein kinase A-activating compounds. Mol Pharmacol 1995;47:757-67.

22. Skouri HN, Dec GW, Friedrich MG, Cooper LT. Noninvasive imaging in myocarditis. J Am Coll Cardiol 2006;48:2085-93.

23. Higasi T, Nakayama Y, Murata A, Sugiyama M, Nakamura K. Clinical evaluation of $67 \mathrm{Ga}$-citrate scanning. J Nucl Med 1972;13:196-201.

24. Lavender JP, Lowe J, Barker JR, Burn JI, Chaudhri MA. Gallium 67 citrate scanning in neoplastic and inflammatory lesions. Br J Radiol 1971;44:361-6.

25. O'Brien K, Barnes D, Martin RH, Rae JR. Gallium-SPECT in the detection of prosthetic valve endocarditis and aortic ring abscess. J Nucl Med 1991;32:1791-3.

26. Pena FJ, Banzo I, Quirce R, Vallina NK, Hernández A, Guede C, et al. Ga-67 SPECT to detect endocarditis after replacement of an aortic valve. Clin Nucl Med 2002;27:401-4.

27. Matsuura $H$, Ishikita $T$, Yamamoto $S$, Umezawa $T$, Ito $R$, Hashiguchi R, et al. Gallium-67 myocardial imaging for the detection of myocarditis in the acute phase of Kawasaki disease (mucocutaneous lymph node syndrome): the usefulness of single photon emission computer tomography. Br Heart $\mathrm{J}$ 1987;58:385-92.

28. O'Connell JB, Henkin RE, Robinson JA, Subramanian R, Scanlon PJ, Gunnar RM. Gallium-67 imaging in patients with dilated cardiomyopathy and biopsy-proven myocarditis. Circulation $1984 ; 70: 58-62$. 